\title{
The Economic Dimension of the Consumption of Chemical Fertilizers in Saudi Agriculture
}

\author{
Adel M. Ghanem, Othman S. Al-Nashwan, Khalid NaharAlrwis, \\ Sharaf Aldin B. Ahmad, Nageeb M. Aldawdahi \\ Department of Agricultural Economics and King Abdullah Bin Abdul-Aziz Food Security \\ Chair, College of Food and Agricultural Sciences, P.O. Box 2460, Riyadh 11451.
}

\begin{abstract}
:
This study aimed at estimation target consumption of chemical fertilizers in Saudi agriculture, by using the Partial Adjustment Model which is a long-term dynamic model. The study results as follow: (1) Despite the crop area decreased by an annual rate of $3.2 \%$, the consumption of chemical fertilizers in Saudi agriculture increased by an annual growth rate of $2.42 \%$ during the period 1990 to 2014 . (2) Share of ground unit (ha) of the total chemical fertilizers increased from $354.6 \mathrm{~kg} / \mathrm{ha}$ in 1990 to $1338.1 \mathrm{~kg} /$ ha in 2014, which increased at an annual growth rate of $4.6 \%$ during the study period. (3) Consumption target of chemical fertilizers in Saudi agriculture are expected to increase from 873.6 thousand tons in 2017 to 1.29 million tons in 2020, an average annual rate estimated at 1.08 million tons during the period 2017-2020. (4) This study recommends the need to reduce the excessive use of chemical fertilizers, especially nitrogen in Saudi Arabia agriculture and to preserve the economic resources and the environment from pollution.
\end{abstract}

Keywords: Consumption; Chemical Fertilizers; Saudi Agriculture.

\section{1- Introduction:}

Many developing countriesin the vertical expansion of agriculture adopted to increase the use of chemical fertilizers and pesticides, leading to environmental pollution as a result of excessive use and unregulated chemical fertilizers, pesticides, and reduced fertility of agricultural land and the weakness of their productivity rate. Because the scarcity of water resources and the difficulty in obtaining them from non-traditional sources, the Kingdom has issued several resolutions aimed at rationalizing water consumption, in addition to the abolition of direct support to the agricultural sector after joining the World Trade Organization at the end of 2005, which led to a decline in crop area from 1.38 million hectares in 1990 to 634 thousand hectares in 2014 (Ministry of Environment, Water and Agriculture, 2017). In spite of the continued decrease in crop area, but the chemical fertilizer consumption increased from 489 thousand tons in 1990 to 848.33thousand tons in 2014. As part of the transformation of organic agriculture policy in order to maintain the economic resources and the environment and produce relatively free of chemical fertilizers, healthy food and raise the Competitiveness agricultural products in international markets, reducing the consumption of chemical fertilizers in Saudi agriculture is required, therefore, adopted the Ministry of Agriculture to develop organic farming project in collaboration with the German organization for Technical cooperation (GTZ)(Al-Qahtani et al, 2011). 


\section{Research objectives:}

This study aimed to identify the economic dimension of the consumption of chemical fertilizers in Saudi Arabia agriculture, through the study of the following objectives:

1- Studying the current status of the consumption of chemical fertilizers in Saudi agriculture.

2- Estimating the target consumption of chemical fertilizers in Saudi agriculture until 2020.

\section{2- Methodology:}

This study is based on the achievement of their goals on the Partial Adjustment Model which is a long-term dynamic model. Partial adjustment model is estimated as an initial step in the short term as follows:

$$
Y_{t}=a h+(1-\lambda) X_{t-1}+b_{1} \lambda X_{1}+b_{2} \lambda X_{2}+b_{3} \lambda X_{3}+\ldots b_{n} / X_{n}+e_{t}
$$

Where: $\lambda$ represent modification factor between zero and right one. A value $\lambda$ near zero to be a small part of the imbalance between the actual situation and the equilibrium is adjusted during one time period, while the value of $\lambda$ the near of the correct one indicates that a large part of the gap between the actual situation and target counterpart is covered during one period of time. Thus, the value $\lambda$ determine Speed of Adjustment, The Adjustment Lag equals $(1-\lambda) / \lambda$ Through adjustment coefficient is derived model in the long run as follows (William, 2003):

$$
=a+b_{1} X_{1}+b_{2} X_{2}+b_{3} X_{3}+\ldots \ldots+b_{n} X_{n}+b_{i}
$$

Where: $\mathbf{Y}_{\mathbf{L}} \mathbf{t}^{\mathbf{T}} \mathbf{C}$ represent a target consumption of chemical fertilizers level, while representing variables $\mathrm{x}_{\mathrm{z}}, X_{\mathrm{z}}, X_{\mathrm{z}}, \ldots X_{n}$ the actual level of variables specific to the consumption of chemical fertilizers in Saudi agriculture. Finally, this study adopted in achieving its goals on secondary data published in the Annual Agricultural Statistical Yearbook and the database for the Food and Agriculture Organization (FAO).

\section{3- Previous studies:}

Addressed some economic studies the use of chemical fertilizers in agricultural production, where Al-Qahtani and Duwais (1992) study which shows that the demand for chemical fertilizers in the Kingdom morally following factors affected fertilizer prices, government support for Agricultural sector (loans and subsidies), and the impact of horizontal expansion in the crop area, and then as the price of other inputs tractor price. Al-Ruwais and Ghanem (2006) study which shows that the reduction of chemical fertilizers and pesticides with increased consumption of organic fertilizers leads to decreased productivity and higher product prices and lower production costs and thus lower gross and net yield. Al-Ruwais and AlNashwan (2006) study which show that in the absence of added chemical fertilizers and pesticides with doubling the use of organic fertilizers and self-sufficiency of the onion crop percentage rate of $86.5 \%$ decline, and thus increasing the quantity and value of Saudi imports of dry onion rates were $19.9 \%, 22.1 \%$ each respectively. It also increases the amount of the deficit in the balance of trade by $23 \%$ and reduced 
exports coverage rate of imports at a rate of 27\%. Mutter (2009) study the impact of chemical fertilizers on soil and the environment in Iraq. It emerged from this study, the presence of environmental risks in the State of Iraq due to the increase of solid and gaseous pollutants that led to an increase in the concentration of both hydrogen and fluorine and phosphorus and sulfates in surface water and groundwater. From the above it is clear that previous studies have shown interest in the effect of reducing the use of chemical fertilizers and pesticides, as well as environmental risks. Therefore, this study differs from previous studies in that it is interested appreciated target consumption of chemical fertilizers in the long term.

\section{4- Results and recommendations}

\subsection{Current status of the consumption of chemical fertilizers in Saudi agriculture:}

It is evident that from the study of the current status of consumption of chemical fertilizers in Saudi Arabia agriculture during the period 1990- 2014, according to data contained in tables $(1,2)$ as follows:

1- Nitrogen fertilizer is considered the most commonly used in Saudi Arabia agriculture, where the average consumption represents $52.89 \%$ of the total average consumption of chemical fertilizers, followed by phosphate and potassium fertilizers increased by $44.30 \%, 2.81 \%$ each, respectively, during the period 1990 2014. Nitrogen fertilizers and phosphate consumption has increased in Saudi Arabia Agriculture by annual growth rates stood at $1.05 \%, 4.50 \%$ each, respectively, while the decline in potash fertilizer consumption rate decreasing is $3.8 \%$ during the study period, due to the adoption of the Kingdom to import only in the fulfillment of Agriculture requirements Saudi Arabia of potassium fertilizers.

2- In spite of decline in crop area at an average annual decrease of $3.2 \%$, but the consumption of chemical fertilizers in Saudi Arabia agriculture increased at an annual growth rate of $2.42 \%$ during the study period, and this means that the crop area is not the variable set for the consumption of chemical fertilizers, but there are other variables led to the excessive use of chemical fertilizers in Saudi agriculture.

3- Share of the land unit (ha) increasedin the total chemical fertilizers from $354.6 \mathrm{~kg} /$ ha in 1990 to $1338.1 \mathrm{~kg} /$ ha in 2014, which increased the share of land unit (ha) of the total chemical fertilizers used in Saudi agriculture by annual growth rate of $4.6 \%$ during the study period. The increase in the average unit share per hectare of chemical fertilizers used in Saudi agriculture in recent years is attributed to the excessive use of nitrogen and phosphate fertilizers starting in 2012, due to the expansion of production and import of these fertilizers, In addition to the Council of Ministers' Resolution 335, which led to a decrease in the area planted with wheat yield at the rate of $12.5 \%$ annually until the wheat disappeared from the crop structure from the beginning of 2016.

4- Comparing the average unit share of the chemical fertilizers of Saudi Arabia to some other countries, it is clear from the data in Table (3) that the average share of the total chemical fertilizers used in Saudi agriculture is more than $558.76 \mathrm{~kg} / \mathrm{ha}$, with an average of $120.9 \%$. Also the average per hectare of the total fertilizer used in Saudi agriculture is higher than that used in agriculture of the Russian 
Federation by $1005.42 \mathrm{~kg} / \mathrm{ha}$, with an average of $6436.7 \%$ during the period 2010-2014.

Table (1): Chemical fertilizer consumption and crop area of agriculture in Saudi Arabia during the period 1990-2014.

\begin{tabular}{|c|c|c|c|c|c|c|}
\hline \multirow{2}{*}{ Year } & \multicolumn{7}{|c|}{ Consumption in thousand tons } & the area cropped & $\begin{array}{c}\text { share of area } \\
\text { unit kg / ha }\end{array}$ \\
\cline { 2 - 5 } & Nitrogen & phosphate & Potash & the total & 1379.18 & 354.6 \\
\hline $\mathbf{1 9 9 0}$ & 273.0 & 193.0 & 23.0 & 489.0 & 1519.76 & 334.3 \\
\hline $\mathbf{1 9 9 1}$ & 284.0 & 200.0 & 24.0 & 508.0 & 1570.82 & 342.9 \\
\hline $\mathbf{1 9 9 2}$ & 292.0 & 218.0 & 28.6 & 538.6 & 1596.41 & 285.0 \\
\hline $\mathbf{1 9 9 3}$ & 250.0 & 190.0 & 15.0 & 455.0 & 1595.55 & 225.6 \\
\hline $\mathbf{1 9 9 4}$ & 196.0 & 155.0 & 9.0 & 360.0 & 1302.36 & 218.1 \\
\hline $\mathbf{1 9 9 5}$ & 153.0 & 121.0 & 10.0 & 284.0 & 1173.31 & 270.2 \\
\hline $\mathbf{1 9 9 6}$ & 171.0 & 138.0 & 8.0 & 317.0 & 1263.26 & 254.1 \\
\hline $\mathbf{1 9 9 7}$ & 181.0 & 131.0 & 9.0 & 321.0 & 1130.49 & 291.9 \\
\hline $\mathbf{1 9 9 8}$ & 200.0 & 121.0 & 9.0 & 330.0 & 1226.51 & 282.9 \\
\hline $\mathbf{1 9 9 9}$ & 210.0 & 128.0 & 9.0 & 347.0 & 1119.95 & 344.8 \\
\hline $\mathbf{2 0 0 0}$ & 228.0 & 137.2 & 21.0 & 386.2 & 1211.58 & 316.7 \\
\hline $\mathbf{2 0 0 1}$ & 223.06 & 141.7 & 19.0 & 383.76 & 1224.50 & 170.7 \\
\hline $\mathbf{2 0 0 2}$ & 98.25 & 104.46 & 6.26 & 208.97 & 1216.04 & 352.8 \\
\hline $\mathbf{2 0 0 3}$ & 250.29 & 164.67 & 14.10 & 429.06 & 1172.74 & 313.3 \\
\hline $\mathbf{2 0 0 4}$ & 230.71 & 130.46 & 6.30 & 367.47 & 1106.73 & 297.0 \\
\hline $\mathbf{2 0 0 5}$ & 182.78 & 136.88 & 9.00 & 328.66 & 1074.16 & 317.3 \\
\hline $\mathbf{2 0 0 6}$ & 228.66 & 106.44 & 5.70 & 340.80 & 1074.96 & 380.9 \\
\hline $\mathbf{2 0 0 7}$ & 255.99 & 132.33 & 21.15 & 409.57 & 971.61 & 266.7 \\
\hline $\mathbf{2 0 0 8}$ & 180.39 & 65.05 & 13.65 & 259.09 & 834.99 & 278.4 \\
\hline $\mathbf{2 0 0 9}$ & 129.26 & 92.40 & 10.80 & 232.46 & 806.68 & 362.8 \\
\hline $\mathbf{2 0 1 0}$ & 165.90 & 119.74 & 7.05 & 292.69 & 787.74 & 594.8 \\
\hline $\mathbf{2 0 1 1}$ & 265.65 & 196.88 & 6.00 & 468.53 & 787 \\
\hline $\mathbf{2 0 1 2}$ & 438.22 & 684.94 & 3.60 & 1126.76 & 745.64 & 1511.1 \\
\hline $\mathbf{2 0 1 3}$ & 360.22 & 534.98 & 6.60 & 901.80 & 694.55 & 1298.4 \\
\hline $\mathbf{2 0 1 4}$ & 335.39 & 500.94 & 12.00 & 848.33 & 634.00 & 1338.1 \\
\hline Average & 231.31 & 193.76 & 12.27 & 437.35 & 1137.34 & 440.14 \\
\hline Surnnnnn \\
\hline
\end{tabular}

Source:

1- Food and Agriculture Organization (FAO), the database, the period from 1990 to 2012.

2- Ministry of Agriculture, the Department of Economic Studies and Statistics, Agricultural Statistical Yearbook, various issues.

Table (2): Statistical analysis of chemical fertilizer consumption in Saudi agriculture during the period 1990-2014.

\begin{tabular}{|c|c|c|c|c|}
\hline The equation & $R^{2}$ & $F$ & $\begin{array}{c}\text { Rate of } \\
\text { growth \% }\end{array}$ & fertilizer \\
\hline 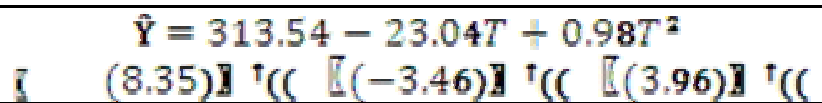 & 0.45 & 9.08 & 1.05 & Nitrogen \\
\hline 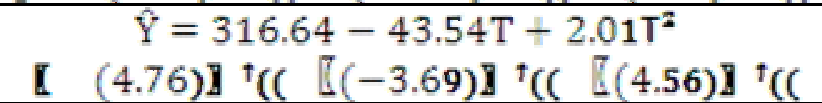 & 0.58 & 14.95 & 4.50 & phosphate \\
\hline 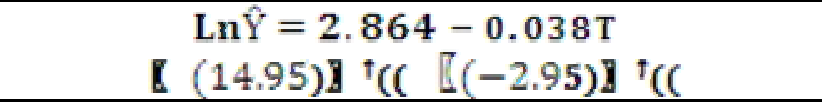 & 0.27 & 8.71 & -3.80 & Potash \\
\hline 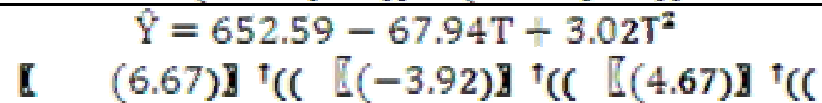 & 0.56 & 14.16 & 2.42 & the total \\
\hline $\begin{array}{c}\operatorname{Ln} \hat{Y}=7.432=0.032 \mathrm{~T} \\
\mathbb{I}(182.27)]^{\mathrm{t}}(\mathrm{C}(-11.97)]^{\mathrm{t}} \mathrm{C}(\end{array}$ & 0.86 & 143.41 & -3.20 & $\begin{array}{l}\text { the area } \\
\text { cropped }\end{array}$ \\
\hline $\begin{array}{c}\operatorname{Ln} \hat{Y}=5.293+0.046 \mathrm{~T} \\
\mathbb{I}(28.90)]^{\dagger}(C)[(3.76)]^{1}(C\end{array}$ & 0.38 & 14.11 & 4.60 & $\begin{array}{c}\text { share of area } \\
\text { unit }\end{array}$ \\
\hline
\end{tabular}

** Significant at level $1 \%$.

Source: compiled and calculated from the data in table (1). 
Table (3): The amount of variation between the average unit share per hectare of the chemical fertilizers of Saudi Arabia and some other countries during the period 2010-2014.

\begin{tabular}{|c|c|c|c|c|c|c|}
\hline \multirow[b]{2}{*}{ country } & \multicolumn{4}{|c|}{ Chemical fertilizers kg/hec } & \multirow{2}{*}{$\begin{array}{c}\text { Amount of } \\
\text { disparity } \\
\mathrm{kg} / \mathrm{hec}\end{array}$} & \multirow{2}{*}{$\begin{array}{l}\text { Relative } \\
\text { change } \\
\text { rate } \%\end{array}$} \\
\hline & Nitrogen & Phosphate & Potassium & Total & & \\
\hline Saudi Arabia & 435.65 & 575.47 & 9.92 & 1021.04 & - & - \\
\hline Egypt & 362.12 & 90.30 & 9.86 & 462.38 & 558.76 & 120.9 \\
\hline Australia & 25.08 & 18.68 & 4.18 & 47.94 & 973.10 & 2029.8 \\
\hline Russia & 9.80 & 3.56 & 2.26 & 15.62 & 1005.42 & 6436.7 \\
\hline U.S.A & 77.98 & 25.10 & 27.40 & 130.48 & 890.56 & 682.5 \\
\hline United Kingdom & 165.90 & 31.36 & 44.08 & 241.34 & 779.70 & 323.1 \\
\hline France & 104.72 & 12.63 & 19.34 & 136.68 & 884.36 & 647.0 \\
\hline Germany & 142.18 & 23.28 & 35.80 & 201.26 & 819.78 & 407.3 \\
\hline
\end{tabular}

Source: Food and Agriculture Organization (FAO), 2010-2014.

\subsection{Estimate target consumptionof chemical fertilizers in Saudi Arabia agriculture:}

The consumption of chemical fertilizers determined by $\left(Y_{t}\right)$ range of economical factors, including: (1) chemical fertilizer consumption in the previous year $\left(Y_{t-1}\right),(2)$ The average real retail ${ }^{*}$ chemical fertilizers price riyal / ton $\left(X_{1 t}\right),(3)$ Domestic production of chemical fertilizers in thousand tons $\left(X_{z t}\right)$, (4) Crop area per thousand hectares $\left(X_{a z}\right),(5)$ the amount of imports of chemical fertilizers in thousand tons $\left(X_{* \tau}\right),(6)$ Total loans and agricultural subsidies in million riyals value $\left(X_{s \tau}\right)$. And perform stepwise Multiple Regression Analysis of the explanatory variables specific to the consumption of chemical fertilizers in Saudi Arabia agriculture during the period 1990 - 2014 in the linear and double logarithm form, Alogarithm model in the short term and might show a preference expressed in the following equation:

$$
\begin{aligned}
& L n Y_{t}=-1.629+0.607 \operatorname{Ln} Y_{t-1}-0.196 \operatorname{Ln}_{1 t}+0.519 \operatorname{Ln} X_{n t}+0.313 \operatorname{Ln} X_{t} \\
& (-2.66)^{*}(3.84)^{*} \quad(-2,14)^{*} \quad(4.21)^{*}(1.96)^{*} \\
& R^{2}=0.76 \quad F=13.68 \quad D . W=1.64
\end{aligned}
$$

It is clear from Parameters estimated that the value of $(1-\lambda)$ in short-term model amounted to 0.607 and then estimated value adjustment coefficient $(\lambda)$ of about 0.393 and those possible to express a long-term model in the following equation:

$$
\operatorname{Ln} X_{t}=-4.145-0.499 \ln X_{1 t}+1.321 \operatorname{Ln} X_{2 t}+0.796 \operatorname{Ln} X_{i t}
$$

It is clear from the estimated model, average real retail chemical fertilizers price increased by $10 \%$ leads to a decrease in target chemical fertilizers consumption at a rate of $4.99 \%$, while showing that an increase in both the production and import of chemical fertilizers by $10 \%$ leads to an increase in target chemical fertilizers consumption at a rate of $13.21 \%, 7.96 \%$ each respectively. And the model's has good ability for predictive, due to the approaching Theil inequality coefficient (U-Theil)

${ }^{*}$ Were calculated using the real retail price index for wholesale prices $(1988=100)$. 


\section{The Economic Dimension of the Consumption of Chemical Fertilizers in Saudi Agriculture}

พq9

from scratch as 0.02 In light Breusch-GodFrey serial correlation LM Test value (F) 1.28 which is not significant statistically, indicating a free estimate of the problem of model autocorrelation of residuals. It also is clear from the Arch Test that value (F) amounted to 0.72 which is statistically significant, indicating that the estimated model does not have a self-link in the chain variation (Vandaele, 1992).

Target chemical fertilizers consumption is predict until 2020, has been predicting of the average real prices and the production and import of chemical fertilizersUsing the general trend models that have good predictive ability according to the values of Theil inequality coefficient (U-Theil) in table (4). It is clear from the data contained in tables $(4,5)$ increase in the average real retail prices of chemical fertilizers from 2.49 riyals thousand / tons year in 2017 to 2.75 thousand riyals / ton in 2020 are expected to increase domestic production of chemical from 2.73 million tons of fertilizer in 2017, to 3.13 million tons in 2020, while import is expected to increase in 2017 from chemical fertilizers 241.7 thousand tons, to 335.5 thousand tons in 2020. In light the predictive values of each of the average real prices and the production and import of chemical fertilizers increased target of chemical fertilizers from 873.6 thousand tons of consumption in 2017 is expected to 1.29 million tons in 2020, an average annual estimated at 1.08million tons during the period 2017- 2020. In light of Resolution No. (335) and Decision No.( 66) on stopping the cultivation of fodder, the study assumes that the crop area will be stable over 2014, amounting to 634 thousand hectares during the period 2017-2020. The average land unit share of chemical fertilizers is expected to increase from 1.38tons / ha in 2017 to 2.04tons / ha in 2020, an annual average estimated 1.69tons / ha during the period 2017-2020.

Table (4): the equations of the general trend of the evolution of the average real retail, production and import of chemical fertilizer prices during the period 1990-2014.

\begin{tabular}{|c|c|c|c|c|}
\hline The Model & $R^{2}$ & $F$ & $\begin{array}{c}\text { U- } \\
\text { Theil }\end{array}$ & Item \\
\hline $\begin{array}{c}\operatorname{Ln} \mathrm{X}_{1}=6.92=+0.032 \mathrm{~T} \\
(44.15)^{*}(2.79)^{*}\end{array}$ & 0.27 & 7.78 & 0.023 & $\begin{array}{c}\text { Average retail } \\
\text { prices Real }\end{array}$ \\
\hline 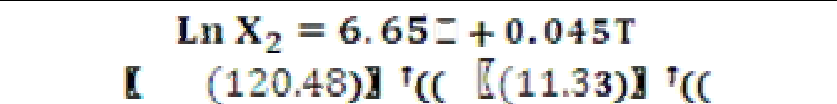 & 0.86 & 128.30 & 0.008 & $\begin{array}{l}\text { Domestic } \\
\text { production }\end{array}$ \\
\hline $\begin{array}{l}\mathrm{X}_{4}=252.07-28.93 \mathrm{~T}+1.02 \mathrm{~T}^{2} \\
\mathrm{I}(11.13) \rrbracket^{\top}\left(C \llbracket(-6.65) \rrbracket^{\dagger}\left(C \rrbracket(5.82) \rrbracket^{\dagger}(C\right.\right.\end{array}$ & 0.72 & 25.68 & 0.138 & $\begin{array}{l}\text { Quantity of } \\
\text { imports }\end{array}$ \\
\hline
\end{tabular}

(C Significant at level $1 \%$.

Source: compiled and calculated from:

1. Ministry of Agriculture, Department of Studies and Planning and Statistics. Annual Agricultural Statistical Yearbook, various issues for the period 1990-2014.

2. Food and Agriculture Organization (FAO), the database, the period from 1990 to 2014.

From the above it is clear that despite the importance of the use of chemical fertilizers to increase agricultural production, but the accumulation of chemical fertilizers leads to soil and groundwater and the high content of nitrogen pollution, then moves on to all of this pollution from the plant, animal and human. According to the finger to the responsibility of chemical fertilizers and pesticides for the spread of many incurable diseases, in addition to an imbalance in the ecological balance. 
Despite the decline in crop area, but the share of floor unit of chemical fertilizers has increased from $354.6 \mathrm{~kg} /$ ha in 1990 to $1338.1 \mathrm{~kg} /$ ha in 2014 , so this study recommends the need to reduce the excessive use of chemical fertilizers, especially nitrogen in Saudi agriculture, to conserve resources economic environment from pollution.

Table (5): predictive values for the average real retail prices, production and import target and consumption of chemical fertilizers during the period 2017-2020.

\begin{tabular}{|c|c|c|c|c|c|c|}
\hline Year & $\begin{array}{c}\text { Average } \\
\text { real retail } \\
\text { prices } \\
\text { Riyals / ton }\end{array}$ & $\begin{array}{c}\text { Domestic } \\
\text { production } \\
\text { Thousand } \\
\text { tons }\end{array}$ & $\begin{array}{c}\text { Quantity } \\
\text { imports } \\
\text { thousand } \\
\text { tons }\end{array}$ & $\begin{array}{c}\text { Target } \\
\text { consumption } \\
\text { thousand } \\
\text { tons }\end{array}$ & $\begin{array}{c}\text { Cropped } \\
\text { area } \\
\text { thousand } \\
\text { hectares }\end{array}$ & $\begin{array}{c}\text { share of } \\
\text { area unit } \\
\text { Kg / ha }\end{array}$ \\
\hline $\mathbf{2 0 1 7}$ & 2497.4 & 2732.6 & 241.7 & 873.6 & 634.0 & 1377.9 \\
\hline $\mathbf{2 0 1 8}$ & 2578.6 & 2858.4 & 270.9 & 999.1 & 634.0 & 1575.9 \\
\hline $\mathbf{2 0 1 9}$ & 2662.4 & 2989.9 & 302.2 & 1138.4 & 634.0 & 1795.6 \\
\hline $\mathbf{2 0 2 0}$ & 2749.0 & 3127.5 & 335.5 & 1292.1 & 634.0 & 2038.0 \\
\hline Average & 2621.9 & 2927.1 & 287.6 & 1075.8 & 634.0 & 1696.8 \\
\hline
\end{tabular}

Source: compiled and calculated from equations in table (3) and the model econometric in long-term.

\section{Acknowledgement}

This research was supported by King Saud University Deanship of Scientific Research. College of food and Agricultural Sciences Research Center.

\section{References:}

1- Al-Qahtani, S. Hussein and Abdul Aziz M. Duwais (1992). Derived demand on chemical fertilizers in Saudi Arabia. The scientific journal of the Faculty of Agriculture, Cairo University, Volume 43, Issue IV, p: 1487-1496.

2- Al-Qahtani, S. Hussein, Adel M. Ghanem, Reda A. Yousef, Mohammed M. Harhash and Radwan M. Yakti (2011). Study of the expected impacts of the application organic Farming and integrated biological control in Saudi Arabia Agriculture.final technical report (AT- 28-9). King Abdulaziz City for Science and Technology.

3- Al-Ruwais, K. Nahar and Adel M. Ghanem (2006). Economic effects of reducing chemical fertilizers and pesticides consumption to produce the most important vegetable crops in the regions of Riyadh, Al-Kharj.Agricultural Research Center, College of Food and Agricultural Sciences.

4- Al-Ruwais, K. Nahar and Othman S. Al Nashwan (2006). The impact of the application of organic farming for onion crop on the Saudi agricultural economy. King Saud University Journal, Agricultural Sciences, Vol. (19), No. (1), Riyadh, $\mathrm{p}: 3-20$. 
5- Food and Agriculture Organization (FAO). Database for the period 1990-2014.

6- Ministry of Environment, Water and Agriculture, Studies, Planning and Statistics Department. Agricultural Statistical Yearbook, various issues, the period from 1990 to 2017.

7- Mutter, M. Ghazi (2009). The impact of chemical fertilizer industry on soil and the environment in Iraq.Qadisiyah Journal of Engineering Science, Vol. 2, No. (4), Faculty of Engineering, Al- Mustansiria University, p: 1-20.

8- Vandaele, Walter (1992). Time series for Applied Perspective and models Box Jenkins. Translation of Abdul MordyHamedAzzam, a review of Ahmed HussainHaroon, Dar Almarekh Publishing, Saudi Arabia, Riyadh.

9- William H. Greene, (2003). Econometric Analysis, Fifth edition, New York University. 